\title{
Novel lipid sources in parenteral and enteral nutrition
}

\author{
BY BRUCE R. BISTRIAN
}

Laboratory of Nutrition/Infection, Department of Medicine, Beth Israel Deaconess Medical Center, Harvard Medical School, Boston, MA 02215, USA

Lipids are an important energy source in the parenteral and enteral nutrition of critically-ill patients because of their high energy density $(37.6 \mathrm{~kJ} / \mathrm{g}$ ) and low osmolarity, although in conventional parenteral nutrition only the recently available $300 \mathrm{~g}$ lipid/1 emulsions $(12.5 \mathrm{MJ} / \mathrm{l})$ are more energy dense than $700 \mathrm{~g}$ dextrose/ $(9.6 \mathrm{MJ} / \mathrm{l})$ as starting components in total parenteral admixtures, e.g. $200 \mathrm{~g}$ lipid// at $8.3 \mathrm{MJ} / 1$ and $100 \mathrm{~g}$ lipid// at $4.2 \mathrm{MJ} / 1$. Lipids also serve as a source of two fatty acids, $\alpha$-linolenic and linoleic, that are essential in human nutrition at less than $0.5 \%$ and about $1.0 \%$ total energy respectively; however, up to $4 \%$ of energy as linoleic acid will further improve $\mathrm{N}$ utilization. Fat-soluble vitamins $(\mathrm{A}, \mathrm{D}, \mathrm{E}, \mathrm{K})$ and other important nutrients which have not been established as being essential (i.e. carotene, lycopene, flavonoids) have improved absorption in the presence of fats. Man is unable to desaturate long-chain fatty acids at either C-3 ( $\alpha$-linolenic) or C-6 (linoleic) from the methyl end $(\omega-C)$ but can at C-9, a situation that results in three common families of fatty acids in human metabolism $n-3, n-6$, and $n-9$. $\alpha$-Linolenic acid $(18: 3 n-3)$ thus serves as the precursor for eicosapentaenoic acid (20:4n-3; EPA) and docosahexaenoic acid (22:6n-3; DHA) and linoleic (18:2n-6) for dihomo- $\gamma$-linolenic acid (20:3n-6; DHLA) and arachidonic acid (20:4n-6; AA) after elongation of the C chains and further desaturation but preservation of their $n-3$ or $n-6$ identity. These latter compounds have unique importance in that they serve as precursors for the eicosanoids (EPA, DHLA, AA) which are ubiquitous second messengers or have unique effects (DHA in vision and brain function, $\mathrm{AA}$ as a second messenger) in addition to their properties as polyunsaturated fatty acids. These three families of fatty acids have numerous interrelationships which have considerable clinical impact. For example, $\alpha$-linolenic acid can be converted in man to EPA or DHA but with limited efficiency (Meydani et al. 1993) which makes this a less-rapid and effective means of increasing the EPA content of membranes. Although $\alpha$ linolenic acid inhibits the elongation and desaturation of linoleic acid to DHLA and AA, EPA has a much larger impact on AA concentration in tissue membrane phospholipids (Wu et al. 1996).

\section{LIPIDS IN CLINICAL NUTRITION}

Fat is a preferred fuel in stressed individuals (Macfie et al. 1981) with maximal benefit at approximately 10-15\% of total energy (Mochizuki et al. 1984; Trocki et al. 1987; Gollaher et al. 1993; Selleck et al. 1994; Garrel et al. 1995). Long-chain triacylglycerols improve $\mathrm{N}$ balance as well as reducing triacylglycerol accumulation in critically-ill animals and human subjects (Macfie et al. 1981; Pomposelli et al. 1986). Excess parenteral administration of parenteral long-chain-triacylglycerol emulsions can impair reticuloendothelial system function in man (Seidner et al. 1989; Jensen et al. 1990) which may have been a factor in the increased morbidity due to infection in patients receiving preoperative total parenteral nutrition containing fat compared with glucose and amino acids alone as the energy source (Muller et al. 1982). It has been stated that the adverse effects of parenteral long-chain-triacylglycerol administration have only been seen when lipid is 
infused at rates greater than total energy expenditure $(0.11 \mathrm{~g} / \mathrm{kg}$ per h; Klein \& Miles, 1994).

\section{ADVERSE EFFECTS OF LIPIDS}

A second proposed mechanism for adverse consequences due to lipid administration has been the dietary $n-3: n-6$ value. Over the tens of thousands of years of an agriculture-based existence, the dietary $n-3: n-6$ remained stable at about 1 ; however, in the past 100 years or so revolutionary changes in the food supply and dietary habits have caused this ratio to fall dramatically, to less than $0 \cdot 1$ (Simopoulos, 1991). There is now considerable evidence that this has provided a more pro-inflammatory condition related to changes in membrane fluidity, to types and amount of eicosanoid production as second messengers in cellular signalling, and to arachidonic acid availability as a second messenger in its own right. AA and EPA are prominent components of the lipid membranes of essentially all cells, and it is when these fatty acids are in the 2-position of membrane phospholipids that their release is provided by the action of phospholipase $\mathrm{A}_{2}$ (EC 3.1.1.4) particularly after cytokine or endotoxin stimulation. The third major family of unsaturated fatty acids is the $n-9$ fatty acids. Oleic acid (18:2n-9) is the counterpart of $\alpha$-linolenic and linoleic acid which can be elongated and desaturated by the same enzymes to produce eicosatrienoic acid (20:3n-9). This compound, also called the Mead acid, is not a precursor for eicosanoids, but does indicate essential fatty acid deficiency when present, because it is only formed when there is insufficient $\alpha$-linolenic or linoleic acid for elongation or desaturation. Although in animal studies essential fatty acid deficiency improves the outcome from endotoxin shock by limiting eicosanoid production, particularly thromboxane $A_{2}$ (Cook et al. 1980), this has limited clinical application, since essential fatty acid deficiency produces severe immunodeficiency. In fact, several of the infants in whom essential fatty acid deficiency in human subjects was first identified, died of infection, as a consequence of consuming a linoleic acid-deficient formula (Hansen et al. 1963).

\section{MARINE OILS}

The reported benefits of marine-oil feeding have been principally attributed to changes in receptor function and signalling efficiency related to membrane fluidity, with greater fluidity with increased polyunsaturation and decreased cholesterol incorporation, and to changes in the type and amount of eicosanoids produced (Kinsella et al. 1990). Fish-oil supplementation has been shown to reduce the production of interleukin-1 and tumour necrosis factor by peripheral blood mononuclear cells in response to endotoxin or plant lectins (Endres et al. 1989), presumably through signal modulation. Eicosanoids arising from AA are prostaglandins (PG), prostacyclins, and thromboxanes of the 2-series and leukotrienes of the 4-series, whereas EPA yields 3-series prostanoids and 5-series leukotrienes. $\mathrm{PGE}_{2}$ is a potent immunodepressant and vasodilator, thromboxane $\mathrm{A}_{2}$ a vasoconstrictor and platelet aggregator, and leukotriene $\mathbf{B}_{4}$ a leukoadherent and permeability-increasing factor; their counterparts arising from EPA are considerably less potent (Hwang, 1989; Kinsella et al. 1990). The reported effects of $n$-3 polyunsaturated fatty acids on immune function have been contradictory (Payan et al. 1986; Meydani et al. 1991; Berger et al. 1993; Wu et al. 1996). These differences have been attributed to varied experimental conditions, including age, species, diet, feeding period etc., but the most prominent factor appears to be tocopherol content (Wu et al. 1996). Although it is widely accepted that higher polyunsaturated fatty acid intake increases the need for tocopherol, 
this has been largely ignored. In this study in primates (Wu et al. 1996) fish oil with adequate tocopherol supplementation improved $\mathrm{T}$ cell-mediated mitogenic response and interleukin 2 production, but this effect was not seen with $\alpha$-linolenic acid, although both fatty acids reduced $\mathrm{PGE}_{2}$ production in $\mathrm{T}$ cells. Similar effects of tocopherol supplementation of fish oil to improve immune function were proposed in human subjects after clinical study (Meydani et al. 1993). In the former study (Wu et al. 1996), the finding that $\alpha$-linolenic acid has less effect than EPA on EPA and AA levels in cellular membranes, $\mathrm{PGE}_{2}$ production, and vitamin $\mathrm{E}$ content as well as immune function support the contention that EPA supplementation appears to be a more potent dietary manipulation.

\section{CLINICAL STUDIES OF MARINE OILS}

Human studies of fish-oil supplementation in enteral and parenteral nutrition are more consistently positive. In burn patients consuming one of three diets differing primarily in fat content, with equal and limited amounts of fish oil and safflower oil (approximately $15 \%$ each of total energy) in one diet, moderate (approximately $12 \%$ of total energy) amounts of maize oil in the second diet and large (approximately $28 \%$ of total energy) amounts of soyabean oil in the third diet, serious nosocomial infections and death were significantly more common in the high-vegetable-oil diet (Gottschlich et al. 1990). Two studies by Daly et al. (1993, 1995) compared a fish-oil-containing diet, which also contained other putative immunostimulatory nutrients (arginine and nucleotides), to two different vegetable-oil diets following major abdominal surgery for cancer of the gastrointestinal tract. Nosocomial infection roles and length of stay were reduced by the experimental diet. A much larger study of the same fish-oil-containing diet in critically-ill patients in intensive care units demonstrated important trends for shortening of hospital stay (Bower et al. 1995). A recent trial in burned patients comparing a moderate (35\% of total energy) fat intake with two low-fat (15\% of total energy) diets with or without fish oil demonstrated lower infectious morbidity and shortened length of stay with both low-fat diets (Garrel et al. 1995), suggesting that level of fat intake may be particularly important. In preliminary form, a recent study in trauma patients who received either glucose and amino acids alone or with the addition of parenteral soyabean-oil emulsion at approximately $40 \%$ of energy content demonstrated substantial prolongation of stay in the intensive care unit, ventilator dependence, and infectious morbidity along with laboratory evidence of cellular immunosuppression in the parenteral fat group (Battistella et al. 1995).

\section{NOVEL LIPIDS}

Most dietary lipids are triacylglycerol compounds which are esters of glycerol and $\mathrm{C}_{12}-\mathrm{C}_{18}$ fatty acids and are designated long-chain triacylglycerols. By convention, $\mathrm{C}_{2}-\mathrm{C}_{4}$ fatty acids are considered short-chain fatty acids and $\mathrm{C}_{6}-\mathrm{C}_{12}$ fatty acids, medium-chain fatty acids. Short-chain and medium-chain fatty acids are found in combination with long-chain fatty acids in quantitatively significant amounts to form a mixed triacylglycerol in only a few naturally-occurring fats. These include about $5 \mathrm{~g}$ butyrate $(4: 0)$ and $10 \mathrm{~g}$ medium-chain fatty acids $(6: 0,8: 0,10: 0$ and $12: 0$ in approximately equal amounts $) / 100 \mathrm{~g}$ total fatty acids in butter and $50 \mathrm{~g}$ medium-chain fatty acids (mostly 12:0) $/ 100 \mathrm{~g}$ total fatty acids in a number of tropical oils (i.e. coconut, babassu, palm kernel). The majority of edible fats contain long-chain fatty acids only. Medium-chain triacylglycerols (MCT) are derived by physical separation of tropical oils which removes lauric acid (12:0) and other long-chain 
fatty acids to leave chiefly caprylic (8:0) and capric acid (10:0) in a $2: 1$ ratio. There are a number of unique aspects of MCT metabolism, including no requirement for micelle formation before absorption, rapid absorption without the need for lipase ( $E C$ 3.1.1.3) action, absorption as medium-chain fatty acids bound to albumin in the portal vein, preferential oxidation, and limited capacity for storage (Bach \& Babayan, 1982). MCT are widely employed in enteral products as diets for special medical purposes and are available as parenteral emulsions in Europe. Physical mixtures of MCT and long-chain triacylglycerols (LCT) have been shown to have a thermogenic effect in animals (Mok et al. 1984) and human subjects (Mascioli et al. 1991), and also to be $\mathrm{N}$ sparing (Mascioli et al. 1991). There is much better clearance by the reticulo-endothelial system without evidence of interference under conditions in which LCT emulsions demonstrate impairment (Seidner et al. 1989).

In clinical study of patients undergoing hepatic resection, peri-operative feeding with total parenteral nutrition including a MCT-LCT emulsion showed reduced infectious morbidity and improved hepatic function supporting their exceptional tolerance in the setting of impaired hepatic function (Fan et al. 1994). However, the thermogenic capacity of MCT, their lack of essential fatty acids, and limited parenteral and enteral tolerance have made them less than ideal substrates under certain circumstances unless combined with long-chain triacylglycerols (Sandstrom et al. 1995).

\section{STRUCTURED LIPIDS}

Structured lipids composed of various chemical combinations of long-, medium-, and/or short-chain fatty acids have unique properties not found in simple physical mixtures that reflect their unique parentage. They are produced by interesterification of mixtures of various triacylglycerols, particularly a long-chain triacylglycerol such as vegetable oil or fish oil, with an MCT. The commercial process of interesterification leads to randomization so that all possible structures are found including LML, LMM, LLM, MLM, MMM and LLL (where $\mathrm{L}$ and $\mathrm{M}$ represent long- and medium-chain fatty acids respectively at positions 1, 2 and 3 respectively of triacylglycerols; Klemann et al. 1994). The structured lipid MLM is more rapidly and efficiently absorbed than a long-chain triacylglycerol (Jandacek et al. 1987). A long-chain fatty acid in position 2, such as linoleic acid or EPA, is preferentially absorbed and preferentially retained to be stored in membrane phospholipids rather than to be oxidized (Jensen et al. 1994; Christensen et al. 1995). Thus, improved fat, as well as linoleic acid, absorption could be anticipated from these two species in malabsorptive states. Compounds in the form of LML and LMM would lead to absorption of the two monoacylglycerols of the medium-chain fatty acid, re-esterification in the intestinal cell as LML, with subsequent lymphatic absorption and appearance in the systemic circulation as a structured lipid. Such compounds have been convincingly demonstrated to improve protein metabolism in a variety of catabolic states in animals (DeMichele et al. 1988; Teo et al. 1989). Parenteral structured lipids have been shown in human subjects to be well tolerated and to have improved oxidation compared with conventional long-chain triacylglycerols.

A recent clinical study of the physiological and clinical consequences of a structured lipid made from a fish oil $(400 \mathrm{~g} / \mathrm{kg})$ and medium-chain triacylglycerol $(600 \mathrm{~g} / \mathrm{kg})$ has been conducted using jejunal feeding in patients after major surgery for upper gastrointestinal cancer (Kenler et al. 1996). Significant improvement in gastrointestinal tolerance to the experimental formula compared with a formula employing a physical mixture of vegetable oil and MCT was found. Furthermore, there was significant improvement in renal, hepatic, 
and immune function also, presumably related to alteration in eicosanoid balance. As has been shown in animals being continuously fed with fats that have a composition that is considerably different from the normal diet composition (Palombo et al. 1996), rapid incorporation of EPA and reduction of AA within several days is characteristic of this mode of feeding, making this a relevant therapeutic option in the critically ill.

\section{CONCLUSION}

In summary, lipids have become an area of intense interest and investigation for use in parenteral and enteral nutrition, given their essentiality in nutrition and protein- and carbohydrate-sparing ability on the one hand, and their prominent potential impact for benefit or harm on the inflammatory response related to their total contribution to energy and their $n-6: n-3$ value on the other. The available evidence is quite strong that the next major advance in clinical nutrition in the critically ill, perhaps equivalent in importance to the dramatic reduction in energy intake now recommended, will be the determination of the optimal lipid type and amount when formulating a complete nutrient admixture.

B. R. B. is a consultant to Stepan Inc. which manufactures structured lipids and receives royalty payments from Sandoz Nutrition related to fish oil.

\section{REFERENCES}

Bach, A. \& Babayan, V. K. (1982). Medium chain triglycerides. An update. American Journal of Clinical Nutrition 36, 950-962.

Battistella, F. D., Widergren, J. T., Anderson, J. T., Siepler, J., Phinney, S. D., Weber, C. S. \& MacColl, K. (1995). A prospective randomized trial of intravenous fat emulsion administration in trauma victims requiring total parenteral nutrition. Journal of Trauma 39, 164.

Berger, A., German, J. B., Chiang, D., Ansari, A. A., Keen, C. L., Fletcher, M. P. \& Gershwin, M. E. (1993). Influence of feeding unsaturated fats on growth and immune status of mice. Journal of Nutrition 123, 225233.

Bower, R. H., Cerra, F. B., Bershadsky, B., Licari, J. J., Hoyt, D. B., Jensen, G. L., Van Buren, C. T., Rothkos, F. M., Daly, J. M. \& Adelsberg, B. R. (1995). Early enteral administration of a formula (Impact) supplemented with arginine, nucleotides, and fish oil in intensive care unit patients: results of a multicenter, prospective, randomized, clinical trial. Critical Care Medicine 23, 436-449.

Christensen, M. S., Hoy, G. E., Becker, C. C. \& Redgrave, T. G. (1995). Intestinal absorption and lymphatic transport of eicosapentaenoic (EPA), docosahexaenoic acid (DHA), and decanoic acids: dependence on intramolecular triacylglycerol structure. American Journal of Clinical Nutrition 61, 56-61.

Cook, J. A., Wise, W. C., Knapp, D. R. \& Holushksa, P. V. (1980). Essential fatty acid deficiency in rats: A new model for evaluating arachidonate metabolism in shock. In Advances in Shock Research, vol. 6, pp. 93-96 [W. Schumar and B. E. Marshall, editors].

Daly, J., Lieberman, M., Goldfine, J., Shou, J., Weintraub, F., Rosato, E. \& Lavin, P. (1993). Enteral nutrition with supplemental arginine, RNA, and omega-3 fatty acids in patients after operation: immunologic, metabolic, and clinical outcome. Surgery 112, 56-67.

Daly, J., Weintraub, F., Shou, J., Rosato, E. \& Lucia, M. (1995). Enteral nutrition during multimodality therapy in upper gastrointestinal patients. Annals of Surgery 221, 322-338.

DeMichele, S., Karlstad, M., Babayan, V. K., Istfan, N. W., Blackburn, G. L. \& Bistrian, B. R. (1988). Enhanced skeletal muscle and liver protein synthesis with structured lipid in enterally fed, burned rats. Metabolism 37, $787-795$.

Endres, S., Ghorbani, R., Kelley, V., Georgilis, R., Lonneman, G., Van der Meer, J., Cannon, J. G., Rogers, T., Kelmner, M. S., Weber, P. \& Dinarello, C. (1989). The effect of dietary supplementation with $n-3$ polyunsaturated fatty acids on the synthesis of interleukin-1 and tumor necrosis factor by mononuclear cells. New England Joumal of Medicine 320, 265-271.

Fan, S. T, Lo, C. M., Lai, E. C., Chu, K. M., Liu, C. L. \& Wong, J. (1994). Perioperative nutritional support in patients undergoing hepatectomy for hepatocellular carcinoma. New England Journal of Medicine 331, 15471552 . 
Garrel, D. R., Razi, M. R., Lariviere, F., Jobin, N., Naman, N., Emptoz-Bonneton, A. \& Pugeat, M. M. (1995). Improved clinical status and length of care with low-fat nutrition support in burn patients. Journal of Parenteral and Enteral Nutrition 19, 482-491.

Gollaher, C. J., Fechner, K., Karlstad, M., Babayan, V. K. \& Bistrian, B. R. (1993). The effect of increasing levels of fish oil containing structured triglycerides on protein metabolism in parenterally fed rats stressed by burn plus endotoxin. Journal of Parenteral and Enteral Nutrition 17, 247-253.

Gottschlich, M., Jenkins, M., Warden, G., Baumer, T., Haven's, P., Snook, J. T. \& Alexander, J. W. (1990). Differential effects of three enteral dietary regimens on selected outcome variables in bum patients. Journal of Parenteral and Enteral Nutrition 14, 225-236.

Hansen, A. E., Wiese, H. F., Boelsche, A. N., Haggard, M. E., Adam, D. J. D. \& Davis, H. (1963). Role of linoleic acid in infant nutrition. Clinical and chemical study of 428 infants fed on milk mixtures varying in kind and amount of fat. Pediatrics 31, 171-192.

Hwang, D. (1989). Essential fatty acids and the immune response. FASEB Journal 3, 2052-2061.

Jandacek, R. J., Whiteside, J. A., Holcombe, B. N., Volpentein, R. A. \& Taulbee, J. D. (1987). The rapid hydrolysis and efficient absorption of triglycerides with octanoic acid in the 1 and 3 positions and long-chain fatty acid in the 2 position. American Journal of Clinical Nutrition 45, 940-945.

Jensen, G. L., Mascioli, E. A., Seidner, D. L., Istfan, N. W., Domnitch, A. M., Selleck, K., Babayan, V. K., Blackburn, G. L. \& Bistrian, B. R. (1990). Parenteral infusion of long- and medium-chain triglycerides and reticuloendothelial function in man. Journal of Parenteral and Enteral Nutrition 14, 467-471.

Jensen, M. M., Christensen, M. S. \& Hoy, C. E. (1994). Intestinal absorption of octanoic, decanoic, and linoleic acids: Effects of triglyceride structure. Annals of Nutrition and Metabolism 38, 104-116.

Kenler, A. S., Swails, W. S., Driscoll, D. S., DeMichele, S. J., Daley, B., Babineau, T. J., Peterson, M. B. \& Bistrian, B. R. (1996). Early enteral feeding in postsurgical cancer patients: Fish oil structured lipid-based polymeric formula versus a standard polymeric formula. Annals of Surgery 223, 316-333.

Kinsella, J. E., Lokesh, B., Broughton, S. \& Whelan, J. (1990). Dietary polyunsaturated fatty acids and eicosanoids: Potential effects on the modulation of inflammatory and immune cells: An overview. Nutrition 6, $24-44$.

Klein, S. \& Miles, J. M. (1994). Metabolic effects of long-chain and medium-chain triglyceride emulsions in humans. Journal of Parenteral and Enteral Nutrition 18, 396-397.

Klemann, L. P., Aji, K., Chrysam, M. M., D’Amelia, R. P., Henderson, J. M., Huang, A. S., Otterburn, M. S. \& Yarger, R. G. (1994). Random nature of triacylglycerols produced by the catalyzed interesterification of shortand long-chain fatty acid triglycerides. Journal of Agricultural and Food Chemistry 42, 442-446.

Macfie, J., Smith, R. C. \& Hill, G. L. (1981). Glucose or fat as nonprotein energy source? A controlled clinical trial in gastroenterologic patients requiring intravenous nutrition. Gastroenterology 80, 103-107.

Mascioli, E. A., Randall, S., Porter, K. A., Kater, G., Lopes, S., Babayan, V. K. \& Blackburn, B. R. (1991). Thermogenesis from intravenous medium-chain triglycerides. Journal of Parenteral and Enteral Nutrition 15, 27-31.

Meydani, S. N., Endres, S., Woods, M. N., Goldin, B. R., Soo, C., Morill-Labrode, A., Dinarello, C. A. \& Gorbach, S. L. (1991). Oral ( $n$-3) fatty acid supplementation suppresses cytokine production and lymphocyte proliferation: comparison between young and older women. Journal of Nutrition 121, 547-555.

Meydani, S. N., Lichtenstein, A., Cornwall, S., Meydani, N., Goldin, B. R., Rasmussen, H., Dinarello, C. A. \& Schaefer, J. (1993). Immunological effects of National Cholesterol Education Oil Panel Step-2 diets with and without fish-derived n-3 fatty acid enrichment. Journal of Clinical Investigation 92, 105-113.

Mochizuki, H., Trocki, O., Dominioni, L., Ray, M. B., Joffe, S. N. \& Alexander, J. W. (1984). Optimal lipid content for enteral diets following thermal injury. Journal of Parenteral and Enteral Nutrition 8, 638-646.

Mok, K. T., Maiz, A., Yamazaki, K., Sobrado, J., Babayan, V. K., Moldawer, L. L., Bistrian, B. R. \& Blackburn, G. L. (1984). Structured medium-chain triglycerides and long-chain triglycerides are superior to physical mixtures in sparing body protein in the burned rat. Metabolism 33, 910-915.

Muller, J. M., Dienst, C., Brenner, V. \& Pichlmaier, H. (1982). Perioperative parenteral feeding in patients with gastrointestinal carcinoma. Lancet i, 68-71.

Palombo, J. D., De Michele, S. J., Lydon, E. E., Gregory, T. J., Banks, P. L., Forse, R. A. \& Bistrian, B. R. (1996). Rapid modulation of lung and liver macrophage phospholipid fatty acids in endotoxemic rats by continuous enteral feeding with $n-3$ and gamma-linolenic fatty acids. American Journal of Clinical Nutrition 63, 208-219.

Payan, D. G., Wong, M. Y. S. \& Chernov-Rogan, T. (1986). Alterations in human leukocyte function induced by ingestion of eicosapentaenoic acid. Journal of Clinical Immunology 6, 402-410.

Pomposelli, J. J., Moldawer, L. L., Palombo, J, D., Babayan, V. K., Bistrian, B. R. \& Blackburn, G. L. (1986). Short-term administration of parenteral glucose-lipid mixtures improves protein kinetics in porta caval shunted rats. Gastroenterology 91, 305-312.

Sandstrom, R., Hyltander, A., Korner, V. \& Lundholm, K. (1995). Structured triglycerides were well tolerated and induced increased whole body fat oxidation compared with long-chain triglycerides in post operative patients. Journal of Parenteral and Enteral Nutrition 19, 381-386. 
Seidner, D. L., Mascioli, E. A., Istfan, N. W., Porter, K. A., Selleck, K., Blackburn, G. L. \& Bistrian, B. R. (1989). Effects of long-chain triglyceride emulsions on reticulo endothelial system function in humans. Journal of Parenteral and Enteral Nutrition 13, 614-619.

Selleck, K. J., Wan, J. M.-F., Gollaher, C. J., Babayan, V. K. \& Bistrian, B. R. (1994). Effect of low and high amounts of a structured lipid containing fish oil on protein metabolism in enterally fed burned rats. American Journal of Clinical Nutrition 60, 216-222.

Simopoulos, A. (1991). Omega-3 fatty acids in health and disease and in growth and development. American Journal of Clinical Nutrition 54, 438-463.

Teo, T. C., De Michele, S. J., Selleck, K. M., Babayan, V. K., Blackburn, G. L. \& Bistrian, B. R. (1989). Administration of structured lipid composed of MCT and fish oil reduces net protein catabolism in enterally fed, burned rats. Annals of Surgery 210, 100-106.

Trocki, D., Heyd, T. J., Waymack, J. P. \& Alexander, J. W. (1987). Effects of fish oil on postburn metabolism and immunity. Journal of Parenteral and Enteral Nutrition 11, 521-528.

Wu, D., Meydani, S. N., Meydani, M., Hayek, M. G., Huth, P. \& Nicolosi, R. J. (1996). Immunologic effects of marine- and plant-derived $n-3$ polyunsaturated fatty acids in nonhuman primates. American Journal of Clinical Nutrition 63, 273-280. 